\title{
La recepción de la historia de conceptos en España. En la encrucijada entre la reflexión teórica y la aplicación práctica
}

\author{
The reception of the history of concepts in Spain. At the \\ crossroads between theoretical reflection and practical \\ application
}

\author{
Luis Fernández Torres \\ https://orcid.org/0000-0001-5023-3150 iD
}

\section{RESUMEN}

En este trabajo se aborda una suerte de historia de la historia de conceptos desarrollada por Reinhart Koselleck. En concreto, se procura trazar su periplo en el mundo académico español, incorporando los inicios de su recepción, los resultados materiales de la aplicación de su propuesta y un esbozo de los grupos de investigadores que han aprovechado críticamente su obra. En este sentido, destacan especialmente dos perfiles, que se corresponden con filiaciones académicas distintas: una vertiente vinculada a la filosofía y otra de corte historiográfico, que reflejan, a su vez, la riqueza de una obra como la koselleckiana, en la que conviven elementos procedentes de distintas disciplinas, como la filosofía, la lingüística y la historia, entre otras. Esta diversidad de componentes se manifiesta en la constitución de un potente cuerpo teórico en combinación con un elaborado aparato metodológico.

\section{PALABRAS CLAVE}

Reinhart Koselleck; Historia de la historiografía; Historia de conceptos

\section{KEYWORDS}

Reinhart Koselleck; History of historiography; History of concepts 
Uno de los cambios más importantes en el conjunto de las ciencias sociales y humanas ha consistido en el progresivo aumento del interés por el lenguaje. La conciencia de ese proceso, que se extiende ya a lo largo de varias décadas, ha ido acompañado, a su vez, de la búsqueda de un punto inequívoco de partida, lo que resulta tentador pero también aquejado de cierta arbitrariedad. No obstante las posibles reticencias con respecto a ese reclamo, la publicación del Tractatus logico-philosophicus puede considerarse a efectos prácticos como el jalón que marca el inicio de un movimiento en el transcurso del cual el análisis del lenguaje pasó a convertirse en algunas propuestas en el núcleo que anudaba los problemas filosóficos (WITTGENSTEIN 2016) al mismo tiempo en que, con algo de retraso, de la historicidad de los fenómenos sociales se pasaba a insistir en la historicidad del lenguaje (FERNÁNDEZ SEBASTIÁN; FUENTES 2004, p. 13).

Ese movimiento general es conocido mediante una expresión que resultó muy afortunada, la de giro lingüístico, según la fórmula acuñada por Gustav Bergmann. Se trata de un término difuso que fue dado a conocer posteriormente por Richard Rorty (1967) y que, entre otras manifestaciones, puede subdividirse en la filosofía analítica de John L. Austin y John Searle y en la hermenéutica de Hans-Georg Gadamer y Heidegger. Por otro lado, su impacto en el ámbito historiográfico se tradujo especularmente en sendas corrientes cuya trazabilidad permite conectarlas en parte con los anteriores modelos filosóficos. En ese sentido, se ha escrito que las distintas tradiciones culturales explicarían en buena medida esa diversidad de filiaciones. Nos encontramos así con que la llamada Escuela de Cambridge está inspirada en la versión analítica de la filosofía del lenguaje en tanto que la hermenéutica provee de sostén filosófico a la Begriffsgeschichte (en adelante, BG) impulsada por Reinhart Koselleck.

Las manifestaciones intelectuales que influyen en ambas tendencias historiográficas no se reducen, desde luego, a las exclusivamente señaladas. La primera reposa también sobre 
las aportaciones del segundo Wittgenstein y sobre la noción de juegos del lenguaje que el filósofo vienés elaboró en esa etapa (WITTGENSTEIN 1988). A su vez, la BG no sólo está vinculada a la tradición filosófica representada por Heidegger y Gadamer, sino que también es deudora, entre otras fuentes, del pensamiento político de Carl Schmitt y, como trasfondo, de las aportaciones del historicismo alemán.

No es este el lugar para hacer una presentación detallada de las deudas y precedentes intelectuales de cada corriente y de sus interrelaciones. Sin embargo, existe un evidente (y necesario) interés en situar el marco general en el que se ha ido desarrollando la reflexión sobre los aspectos teóricos y metodológicos de la historia de conceptos y sus rasgos más debatidos, así como sobre su aplicación al trabajo empírico, lo que exige ir más allá de su perímetro. La causa de esto último tiene que ver con una afinidad evidente entre las dos tendencias fundamentales de la semántica histórica que no oculta diferencias cruciales que afectan a la selección de la unidad de análisis (discurso y lenguaje frente a concepto), de la unidad temporal (modernidad temprana frente a siglo XVIII y XIX), del aspecto del lenguaje enfatizado (pragmática frente a semántica histórica) y, forzando la comparación, del formato de publicación privilegiado (monografías frente a diccionarios). Por esa razón, resulta imposible no hacer referencias cruzadas, ya que las diferencias entre ambas corrientes apuntan a aspectos problemáticos de la propuesta koselleckiana explotadas por sus detractores y que los investigadores que han hecho uso de sus herramientas heurísticas han debido, en distinto grado, afrontar críticamente.

No obstante, y sin llegar a establecer una distinción radical entre las dos aproximaciones mencionadas, agrupadas bajo el paraguas de la semántica histórica, que eclipse las fricciones e influencias recíprocas que se han dado entre ellas, el objetivo de este trabajo consistirá esencialmente en poner el foco en la segunda de esas formulaciones con el fin de esbozar una historia de la historia de conceptos tal y 
como ha sido (y es) asimilada y practicada entre los investigadores españoles.

Por otro lado, ¿dónde se encuentra el interés concreto de incidir una vez más, siquiera de forma escueta, en los orígenes y filiaciones de la historia de conceptos, tratadas sobradamente en multitud de lugares? Además de esbozar una suerte de mapa de coordenadas de esa aproximación metodológica, su aportación para este trabajo radica en mostrar, aunque sea de forma sucinta, cómo la complejidad de las fibras intelectuales que se enlazan en el proyecto desarrollado por Reinhart Koselleck - en el que se entrevera la filosofía del lenguaje con la teoría política y la historia social (KOSELLECK 1993, p. 105-126) - condicionan su recepción y aplicación en un entorno académico concreto.

Apenas un contacto fugaz con ese enfoque basta para apreciar una ambición teórica, completada con su correlativa apuesta metodológica, que contrasta con el trabajo presente en buena parte del gremio de historiadores. La imbricación y el énfasis puesto en ambos aspectos, al tiempo que lo diferencian de su entorno académico, dotan a la obra de Koselleck de un atractivo especial para un amplio abanico de disciplinas. Especialmente sensibles a ella han sido los filósofos (en lo que respecta a la teoría) y los historiadores, que se han centrado sobre todo en la aplicación práctica de las herramientas heurísticas.

A pesar del desigual énfasis presente en ambos campos, hay un cierto grado de coincidencia entre ellos. Cabe señalar, no obstante, que, si bien la constatación de tal coincidencia justifica no aislarlos mutuamente, no basta para llegar a identificarlos del todo. La construcción intelectual de Koselleck, calificado por Gadamer como un "historiador pensante" (ONCINA COVES 2007, p. 36), independientemente de lo imperfectos o inacabados que puedan estar algunos de sus pilares básicos, está elaborada bajo el signo de una íntima relación de la práctica con la teoría y viceversa. En consecuencia, deshacerse de uno de esos polos conlleva el riesgo de per- 
judicar la productividad de su propuesta. Los rasgos que la definen le proveen, por tanto, de una textura poco habitual que parece exigir la superación de los límites disciplinarios. Esta dualidad en tensión permite entender en parte las formas concretas que ha adoptado su desarrollo en estas latitudes. Las diferentes fases en que puede dividirse esta parcela de la historia de la historiografía española muestran así cómo el incremento de la divulgación de la obra de Koselleck en un primer momento implicó, en una segunda fase, simultáneamente a una confrontación crítica y aplicación práctica, la formación de las dos tendencias mencionadas, que enfocan la apuesta teórica y metodológica del autor desde ángulos distintos enraizados en la propia riqueza de su proyecto intelectual.

Además, ateniéndose a esa división, es posible identificar la serie de elementos, caracterizados en algún caso por un alto grado de generalidad, en la que se desagrega este particular proceso de recepción de la historia de conceptos y que consiste en la divulgación, la organización de proyectos de investigación, la reelaboración de los presupuestos teóricos y metodológicos de Koselleck y su aplicación práctica. Estos aspectos, que servirán de ejes sobre los que pivotará este trabajo, han impregnado de forma desigual los diferentes enfoques. Tres de los puntos mencionados (divulgación, organización y aplicación práctica) han sido indistintamente llevados a cabo por autores que pueden encuadrarse tanto en el campo de la filosofía como en el historiográfico. La reelaboración, por el contrario, se corresponde fundamentalmente, salvo algunas excepciones, con la orientación filosófica. El carácter dual que presenta la obra de Koselleck se ve por tanto reflejado en las apuestas concretas en que se ha plasmado su enfoque.

Antes de dar paso al cuerpo principal del texto, debo hacer una advertencia. A pesar de que el objetivo general de este trabajo aspira a esbozar el proceso global de recepción de la historia de conceptos, el lector podría apreciar en sus páginas 
una querencia hacia el ámbito historiográfico, que se hace visible en la discusión crítica de algunos pasajes y que, en todo caso, cabe atribuir a mis propios intereses académicos.

$$
* * *
$$

Desde la vertiente historiográfica, la atención que fue despertando la semántica histórica generó una búsqueda de paternidades autóctonas, es decir, de las vetas de sensibilidad lingüística presentes en la historiografía española con anterioridad a la recepción de la BG en la Península Ibérica.

Lo cierto es que la introducción de las diversas aproximaciones lingüísticas a la historia vino precedida por una lenta expansión nacional sobre el estudio de los lenguajes políticos, que, con diferentes intensidades según el caso, reconocía la historicidad inherente a dichos lenguajes. Entre los precursores de esos estudios ocupan un lugar especial Rafael Lapesa, María Cruz Seoane, Juan Marichal, Vicente Llorens, Ma Paz Battaner, Pedro Álvarez de Miranda, Antonio Maravall, Luis Díez del Corral, Ortega y Gasset y Manuel Pérez Ledesma, entre otros. Al igual que sucedió en otras partes de Europa, esa nueva sensibilidad supuso en definitiva una superación parcial de la historia de las ideas a lo Meinecke (la Ideengeschichte), de la History of ideas de Lovejoy y de la Histoire des ideés politiques de Chevallier y de Touchard.

Junto a esos antecedentes, que en mayor o menor grado comparten con la historia de conceptos alemana preocupaciones por el lenguaje, lo cierto es que el desvelamiento de las causas próximas del desarrollo en España de esa reciente práctica historiográfica obliga a dirigir la mirada al plano internacional y, concretamente, al contacto con grupos ya formados de investigadores. De este modo, más allá de la fase inicial de divulgación, la parte fundamental del origen de la estructura investigadora nacional (e iberoamericana) en su faceta historiográfica debe buscarse en la experiencia adquirida en los encuentros académicos que, desde su fundación en 1998, organiza el colectivo History of Political and Social Concepts 
Group (HPSCG), denominación que adquiriría posteriormente una formulación más abreviada (y abarcadora), la de History of Concepts Group (HCG) (FERNÁNDEZ SEBASTIÁN; FERNÁNDEZ TORRES 2017, p. 157).

\section{Divulgación}

A comienzos de la última década del siglo $\mathrm{XX}$, aparecieron de forma desconectada una serie de textos que sólo retrospectivamente han adquirido una cierta unidad analítica como partes constituyentes de lo que he identificado como la primera etapa del proceso de recepción y divulgación del proyecto de Koselleck en las publicaciones académicas españolas. Entre ellos destacan los pertenecientes a Joaquín Abellán (1991), Lucian Hölscher (1996) y Pedro Ruiz Torres (1994). El carácter introductorio del primero contrasta con el abordaje de aspectos específicos de los siguientes, centrados, respectivamente, en la relación palabra-objeto y en la naturaleza del tiempo histórico.

Naturalmente, esos hitos inaugurales no deben interpretarse como estrictamente coetáneos a un conocimiento cabal del conjunto de las aportaciones de Koselleck en el ámbito universitario español. Su proyecto ya era conocido con algo de antelación. Si nos tomamos la libertad (quizá algo arriesgada) de hacer extensiva al conjunto del entramado universitario español la experiencia al respecto de una de sus parcelas, podríamos concluir que fue a mediados de los ochenta cuando empezó a hacerse un hueco la labor del historiador alemán en España (SÁNCHEZ-PRIETO 2012, p. 499). Esta apreciación permite aquilatar el valor real de la sorprendente - por temprana (y pronto olvidada) - recepción de su escrito de habilitación Crítica y crisis. Un estudio sobre la patogénesis del mundo burgués (KOSELLECK 1965) a mediados de los años sesenta, en pleno franquismo, que debe entenderse en un contexto de motivaciones no exclusivamente académicas (ONCINA COVES 2003a, p. 225), dando paso a un largo periodo de silencio que, como vemos, recién sería tímidamente roto décadas después. 
La penetración del pensamiento de Koselleck en el ámbito filosófico se produciría un poco más tarde, a partir de los años noventa (VILLACAÑAS 2009), y no, contra lo que cabría pensar en un primer momento, por medio de una relación directa con el entramado académico de origen, sino, fundamentalmente, mediante la relación con un grupo asentado en la Universidad de Padua, que, de la mano de Sandro Chignola y Giuseppe Duso, abordó en una serie de trabajos la constitución del Estado moderno (MARTÍN GÓMEZ 2011, p. 273).

Como ha ocurrido con otras tendencias metodológicas, la cronología de la recepción muestra que también en este caso el diálogo con la historia de conceptos fue algo tardío. En ese sentido, y centrándose en el campo historiográfico, su variedad e intercambio con otras corrientes han llegado a ser tachados de pobres debido a su escaso recorrido en nuestra geografía (HERNÁNDEZ 2010, p. 286). Quizá este sea un aserto válido para los titubeantes comienzos de la disciplina, pero que no hace justicia a sus ulteriores desarrollos.

No obstante su escasez, la producción de los años noventa representó el punto de partida de un crecimiento comparativamente exponencial de las publicaciones que compendian y aplican los presupuestos metodológicos propuestos por Koselleck. De ese modo, desde comienzos del nuevo siglo, junto a la proliferación de artículos de carácter introductorio, encontramos textos que muestran una variedad de intereses en su aproximación: están los que incorporan la metodología propuesta por Koselleck a la investigación empírica, aquellos que confrontan críticamente diversos aspectos de su obra y los que la sitúan en un marco intelectual más amplio, poniéndola en conexión con las aportaciones, entre otros, de Heidegger, Nietzsche, Benjamin y Hannah Arendt (GÓMEZ RAMOS 2007; ROMERO CUEVAS 2008).

Es significativa a ese respecto la publicación de un reguero de números monográficos dedicados a tal enfoque, concentrados, no por casualidad, casi exclusivamente en la primera década del presente siglo. Es el caso del volumen 27 de 
Historia contemporánea (2003), del número 53 de la revista Ayer (2004), de Isegoría (n 37, 2007) y del quinto número de Conceptos. Revista de Investigación graciana, publicado un año después. En esta lista debe incluirse también la Revista de Estudios Políticos ( $\left.{ }^{\circ} 134,2006\right)$ y, por último, el dossier publicado en Anthropos (n० 223, 2009).

Con ello se daba satisfacción a una demanda en aumento de textos que se ocupasen de la obra del historiador germano en su conjunto y complejidad ante la virtual ausencia de un número relevante de trabajos previos. Puede hablarse de la superación de un umbral que, en una periodización provisional, serviría para separar una etapa de relativo desconocimiento de dicha obra de una fase de creciente interés, caracterizada por la expansión relativa del proyecto koselleckiano en el mundo académico español. Lo que se gestó a lo largo de esos años fue, en definitiva, una masa crítica capaz, por un lado, de afrontar una lectura propia de carácter sistemático y, por otro, de iniciar proyectos que pusiesen en práctica las competencias adquiridas.

\section{Traducciones}

Otra clara muestra del interés por la historia de conceptos es el constante aumento de traducciones de la obra de Koselleck. Sabemos que a la ya mencionada versión española de Kritik und Krise le siguió un largo periodo de aparente indiferencia por hacer accesible al lector hispanohablante una obra en expansión; periodo que duró, al menos, hasta 1993, cuando se tradujo Futuro Pasado (KOSELLECK 1993), obra que reúne algunos de los principales artículos teóricos y metodológicos del pensador alemán.

Actualmente contamos con traducciones de sus principales textos, si bien se muestra alguna ausencia notable, como sucede con Preussen. Zwischen Reform und Revolution (KOSELLECK 1967a) o con algunos trabajos clave en los que se plasman las directrices de su proyecto de diccionario concep- 
tual. Su artículo "Richtlinien für das Lexicon politisch-sozialer Begriffe der Neuzeit" (KOSELLECK 1967b), que sentó las bases del futuro lexicón, es una de las carencias más llamativas. En cambio, hace ya más de una década de la publicación en español de su conocida introducción al diccionario Geschichtliche Grundbegriffe (en adelante, GG) (KOSELLECK 1972), otro de los principales textos programáticos en los que está delineada su propuesta metodológica (KOSELLECK 2009).

La puesta al día ha sido costosa. Y esto no es exclusivamente achacable al retraso o desinterés de la recepción. Buena parte de la obra de Koselleck no era fácilmente accesible, ni siquiera en universidades alemanas, y se encontraba repartida en multitud de publicaciones distintas. Ese verdadero "archipiélago textual" fue ordenado en parte mediante una serie de compilaciones publicadas en Alemania a lo largo de la primera década de este siglo, preparando el camino para una sensible mejora de la recepción y conocimiento de la obra de Koselleck en otras comunidades lingüísticas. Fue el caso de Zeitschichten (2000), Begriffsgeschichten (2006) y Vom Sinn und Unsinn der Geschichte (2010).

En ese contexto y en consonancia con el aumento de las publicaciones que de una u otra forma interactúan con la panoplia teórico-metodológica de la historia conceptual, las traducciones del alemán llevadas a cabo en España no han hecho sino aumentar. De este modo, la falta de disponibilidad inicial se ha ido viendo subsanada hasta el punto de que, cada poco tiempo, aparece en los anaqueles de las librerías un libro o capítulo recién traducido. La colección de artículos agrupados en Zeitschichten fue, por ejemplo, vertida al español en los tres años subsiguientes en dos publicaciones sucesivas: Los estratos del tiempo: estudios sobre la historia (KOSELLECK 2001) y Aceleración, prognosis y secularización (KOSELLECK 2003). La misma tendencia fue visible en el caso de la recepción de Begriffsgeschichten, volcada parcialmente en Historias de conceptos (KOSELLECK 2012). 
En este marco, debe subrayarse que los prólogos e introducciones a las obras de Koselleck publicadas en español han sido un vehículo para exponer las bases de su pensamiento e incidir críticamente en sus zonas grises. Es el caso del nada desdeñable texto compuesto por Faustino Oncina y José Luis Villacañas que prologa la traducción de Histórica y Hermenéutica, que tuvo (y sigue teniendo) un importante eco (KOSELLECK 1997; JIMÉNEZ 1999). La producción intelectual de Villacañas revela un perfil de investigador peculiar en el entorno académico español por combinar la faceta teórica y la empírica de un modo más equilibrado de lo que es habitual. Fuera de nuestras fronteras, aunque sin salir del mundo iberoamericano, habría que acudir al ejemplo de Elías Palti, investigador argentino, para encontrar un enfoque que, con otras particularidades, afronta de forma conjunta los retos teóricos y metodológicos que plantea la propuesta koselleckiana.

\section{Críticas a los orígenes}

La recepción de la BG tampoco ha carecido de críticas a sus orígenes intelectuales. En España, esta falla ha sido fundamentalmente puesta de relieve desde la reflexión más filosófica. Muchas de las objeciones llevan hasta Otto Brunner, coeditor del GG desde 1972 hasta 1982, año de su fallecimiento. En su trabajo llevó a cabo una doble crítica del liberalismo. Pretendió subrayar con sus investigaciones, por un lado, la naturaleza contingente del orden liberal-burgués del siglo XIX, superado en los años treinta por el nacionalsocialismo (MELTON 1996, p. 22), y, por otro, la falta de valor explicativo de la historiografía liberal, que aplicaba retrospectivamente sus categorías al pasado (p. 26).

Algunos de los rasgos de los orígenes de la historia conceptual alemana no extienden necesariamente su lastre al devenir ulterior del enfoque considerado en su conjunto. Sin embargo, las críticas al sesgo conservador de esa aproximación no han dejado de acompañar su trayectoria posterior. Como subrayaba Faustino Oncina, Habermas pudo así acusar a 
Koselleck de "haberse alineado con la revolución conservadora" y de apostar por la "urbanización de la provincia schmittiana" (HABERMAS 1975, p. 384-386 apud ONCINA COVES 2003c, p. 184).

Es precisamente Oncina el autor que más se ha hecho eco de unas raíces intelectuales cuanto menos complejas sobre las que, a su juicio, no se ha realizado un ejercicio de autocrítica (ONCINA COVES 2003b, p. 33). El filósofo valenciano ha abundado en el cariz conservador de algunos de los presupuestos de Koselleck a partir de la idea negativa de éste sobre la naturaleza de la Ilustración. Koselleck se habría mostrado crítico con respecto a la moralización de la historia en el seno de una modernidad desbocada (ONCINA COVES 2003b, p. 22-24). Se trata de unos presupuestos que, por otra parte, Koselleck habría modificado parcialmente, según Melvin Richter, en la voz Crisis del GG (KOSELLECK 1972-1997, v. 3). No obstante, en su macrodiccionario habría continuado con la idea ya expuesta en Kritik und Krise, la de que somos el producto de aquel proceso histórico, caracterizado por un conflicto político que bordea (cuando no cae en ellos) procesos revolucionarios. A ello se suma que Koselleck no se haya "atrevido a entablar una discusión sobre su proceso de autoconstitución" (ONCINA COVES 2003a, p. 233).

El conservadurismo que impregna el proyecto intelectual de Koselleck ha sido también puesto de manifiesto por otros autores; a veces duramente, llegándose a intentar calibrar el grado de antiliberalismo presente en su obra y elevándoselo a la categoría de elemento unificador del conjunto de su trabajo teórico. Esta toma de posición reflejaría la fuerte deuda de Koselleck con algunos de los principios intelectuales schmittianos que animan su proyecto. La tardanza de su penetración en España respondería, así, tanto a la "debilidad de la academia española" como al origen "filonazi" de algunas de las influencias intelectuales del historiador alemán (GALINDO HERVÁS 2009, p. 44-45). Tampoco Juan María Sánchez-Prieto, uno de los autores que más atención ha prestado entre nosotros a la 
historia de conceptos, ha dejado de señalar esa vinculación y "fama de schmittiano" de Koselleck. Fama de la que tampoco se libró otro de los referentes de Sánchez-Prieto, Gadamer, debido a su postura ante el nacionalsocialismo, calificada de acomodaticia (SÁNCHEZ-PRIETO 2012).

\section{Proyectos de investigación}

Este apartado requiere recuperar de nuevo la idea relativa a la vinculación entre las diferentes disciplinas que convergen en la obra koselleckiana y su articulación en unos proyectos concretos de investigación que siguen, en general de manera más rígida que su inspirador, las fronteras entre las diferentes disciplinas académicas. Esta desigual relación con la pluralidad de ciencias humanas permite afirmar la existencia de una conexión entre la biografía institucional de los investigadores que dialogan con las formulaciones de la historia conceptual y un uso selectivo del entramado teórico-metodológico original. Esta actitud es imputable, por tanto, en buena medida, a la adscripción académica de los autores y a la propia naturaleza de los conceptos, entendidos en clave koselleckiana. De ese modo, cabe distinguir entre tendencias más teóricas frente a otras empíricas 0 , en otras palabras, entre tendencias de corte filosófico frente a otras que enfatizan la aplicación de la historia conceptual a la investigación histórica. Este carácter bifronte se ha concretado en definitiva en la formación, en estos años, de dos núcleos de investigadores. Se trata de una diversidad de orientaciones pronto evidente para el propio mundo universitario (MARTÍN GÓMEZ 2011, p. 269-270).

A grandes rasgos, la vertiente filosófica comenzó articulándose sobre un "corredor mediterráneo" que comunicaba Valencia y Murcia, destacando entre sus promotores Faustino Oncina y José Luis Villacañas. Este último, coincidiendo fundamentalmente con su etapa en la Universidad de Murcia, gestó un equipo cuyos resultados se plasmaron en parte en la creación de Res Publica. Revista de la historia y del presente de los conceptos políticos. La aproximación desde la historiografía 
surgió, por otro lado, en torno a un proyecto de investigación coordinado por Javier Fernández Sebastián (Universidad del País Vasco) y Juan Francisco Fuentes (Universidad Complutense) con el objetivo de aplicar la experiencia del diccionario alemán al contexto español.

Apuntaba anteriormente que los rasgos propios de la propuesta koselleckiana hacen casi inevitable su atractivo para distintas disciplinas. Esos rasgos son, fundamentalmente, su énfasis teórico en el proceso de modernización, en la naturaleza del tiempo histórico y en la existencia de una pluralidad de modernidades; y su faceta metodológica, guía del proceso de investigación empírica. El primero alimenta las recepciones peninsulares de corte más filosófico, que, por el contrario, parecen haber sido orilladas, desde el frente de la historia, a favor del énfasis en el método, abordado a su vez tangencialmente desde la filosofía.

La división planteada peca, desde luego, de un exceso de estilización, dado que, si bien revela algo, lo hace delineando unos contornos demasiado generales. Lo cierto es que el interés por la aplicación del utillaje heurístico al estudio de casos concretos no se restringe a la historia, del mismo modo que las incursiones en los aspectos más teóricos no son coto exclusivo de la filosofía. Por otra parte, la metodología tampoco ha sido descuidada. El desarrollo de nuevas herramientas heurísticas está asimismo presente. La noción de "momento conceptual", planteada como tipo ideal weberiano y referida a la fase en la que un concepto experimenta modificaciones semánticas fundamentales y a su periodo de máxima vigencia, persigue precisar los instrumentos de captación de las transformaciones conceptuales (CAPELLÁN 2011, p. 122; 2018).

Es evidente que no hay una separación tajante en la obra de Koselleck entre los dos ámbitos, por lo que no cabe esperar que ésa, aun influyendo en la materialización de centros de investigación con intereses distintos, se reproduzca como si de una frontera impermeable se tratase. Es difícil que la práctica de la historia de conceptos escape a la interdisciplinariedad 
cuando su propio origen en Koselleck, acusado de veleidades filosóficas, la ejemplifica.

Sin embargo, las relaciones entre ambos modos de enfocar la historia conceptual no parecen estar exentas de problemas. La doble faz de la obra de Koselleck ha caracterizado inevitablemente la naturaleza de su recepción, estableciendo una relación compleja entre sus diferentes dimensiones en la que el aprovechamiento de las propuestas del autor convive con enmiendas de distinto grado tanto desde la filosofía como desde la historiografía. Este aspecto ha sido recogido en España. Una vez más fue Oncina quien resaltó la ambivalencia con la que ha sido recibida la obra koselleckiana, como indica elocuentemente el epígrafe con el que abre uno de sus artículos. Koselleck sería un "intruso para dos gremios", un personaje marginal (Aussenseiter), incómodo para historiadores y filósofos (ONCINA COVES 2007, p. 35-36), que combina en dosis variables contenidos procedentes de ambas disciplinas.

En ese sentido, ha habido voces que han defendido la necesidad de establecer una perspectiva histórica bien delimitada. Es la intención de Javier Fernández Sebastián en un artículo en el que reflexiona acerca de las dificultades que surgen de determinados intentos de conciliar la aproximación filosófica y la histórica (FERNÁNDEZ SEBASTIÁN 2004). En su opinión, la tendencia a preservar un ámbito libre del perspectivismo del historiador que investiga las ideas políticas del pasado supone establecer un espacio que no existe. Como propuesta alternativa, aboga por asumir la radical historicidad del conocimiento, así como por abordar de forma más sistemática el estudio de los conceptos y lenguajes políticos del pasado, afinando la distinción entre la perspectiva filosófica y la histórica. Es inevitable, afirma, que surjan "dilemas y disyuntivas incompatibles" si se intenta utilizarlas simultáneamente; y añade a continuación que "si ese debate tiene lugar en el interior de un mismo individuo el riesgo de una esquizofrenia metodológica es probablemente muy alto" (FERNÁNDEZ SEBASTIÁN 2004, p. 142). 
A pesar de los esfuerzos por delimitar las respectivas esferas, la dualidad teórico-práctica que atraviesa el proyecto de Koselleck plantea desafíos difícilmente superables a los intentos de establecer distinciones precisas. No en vano, como ya he señalado, en la práctica, el carácter dual impregna en cierto grado las actividades de las dos tendencias. Poner el foco en la labor que se lleva a cabo desde el ámbito de la filosofía española sensible a las propuestas de Koselleck nos permite observar cómo se ramifican sus trabajos. El interés por los aspectos netamente teóricos se ve enriquecido, así, por incursiones en las que el utillaje de la historia de conceptos sirve para indagar en un heterogéneo grupo de campos. De esta forma, estudios de caso pertenecientes a épocas diversas conviven con la comparación entre disciplinas teóricas afines a la historia de conceptos, como la lingüística, la metaforología de Hans Blumenberg, las propuestas de Joachim Ritter y de Reichhardt, la historia de los discursos de la Escuela de Cambridge, la semiótica y la historia de las constelaciones de Dieter Henrich (ONCINA COVES 2017; GÓMEZ RAMOS 2017).

La querencia estructural a la comunicación entre las dos dimensiones ha llevado a que, junto a opiniones que apuestan por delimitar las dos orientaciones básicas en las que se desdobla la práctica nacional, haya quien promueva la necesidad de un diálogo permanente entre ellas si se quiere sacar todo el rendimiento a la historia de conceptos (MARTÍN GÓMEZ 2011, p. 275). En este sentido, probablemente haya que interpretar la advertencia sobre la posible "esquizofrenia" provocada por la combinación de ambos enfoques como un aviso ante el riesgo de una mezcla apresurada.

Esa actitud conciliadora puede interpretarse como generalizada a tenor de la organización de encuentros académicos y publicaciones conjuntas entre representantes de las dos corrientes, lo que obliga a matizar la rotundidad del anterior posicionamiento (FERNÁNDEZ SEBASTIÁN; CAPELLÁN 2011). Aun sin llegar a identificarse, las dos aproximaciones "se han afanado en lograr cauces de colabora- 
ción y en aumentar el respectivo caudal teórico-práctico" (ONCINA COVES 2013, p. 21 y 26). Para un sector, el objetivo de reforzar las relaciones entre la filosofía y la historia consistiría en la elaboración de "una teoría histórica minima". La Histórica (Historik), según resalta Oncina, fue de hecho la propuesta del propio Koselleck para gestar esa combinación (ibíd., p. 19). No está de más recordar que esa Histórica posee un carácter prelingüístico que la diferencia de la historia (Historie) empírica. Su propósito es "hacer inteligible por qué acontecen historias, cómo pueden cumplimentarse y asimismo cómo y por qué se las debe estudiar, representar o narrar" (KOSELLECK; GADAMER 1997, p. 70). Sobre todo en la vertiente filosófica, esta teoría de las condiciones de toda historia posible genera una atracción especial a la que se recurre con frecuencia para interrogarla acerca de su naturaleza, potencial y límites.

Entre los beneficios derivados de esa combinación, se contaría la provisión de recursos para superar los proyectos de investigación historiográficos que hasta ahora se han centrado mayoritariamente en la elaboración de macrodiccionarios y, así, ampliar el espectro para pasar a ocuparse de las bases que rigen la modernidad y nuestra concepción de lo político (MARTÍN GÓMEZ 2011, p. 276). En efecto, los Ilamamientos a rebasar el estudio centrado en conceptos (en buena medida vinculado a los lexicones) se han convertido en una constante con independencia de la disciplina de origen.

Precisamente sobre los rasgos de la producción con formato de diccionario, que ha ido tomando forma a lo largo de los últimos 15 años, y la problemática asociada es que tratarán las siguientes páginas. Ese género ha estado condicionado, de modo general, por una tríada categorial que ha estructurado y delimitado el área de trabajo. Conceptos, espacio territorial y periodización se han hilvanado estrechamente, posibilitando un esfuerzo académico notable si bien con efectos limitadores en otros aspectos. En sendos epígrafes presentaré cómo se han planteado los problemas detectados que afectan directa- 
mente a cada una de esas dimensiones y cuáles han sido las soluciones propuestas entre quienes se han ocupado de la historia de conceptos en España.

\section{Críticas al lexicón y primacía de los conceptos}

El formato adoptado en la historia de conceptos y sus presupuestos metodológicos no han estado libres de críticas, ásperas en ocasiones. La ordenación alfabética y la primacía de los conceptos que lleva asociada, por contraposición a su integración en unidades de análisis más amplias, han sido percibidas como una cuestión problemática que ha dado lugar a serias dudas. En ese contexto se ha llegado a defender la paralización del proyecto y una nueva orientación dirigida a explorar campos conceptuales y argumentaciones (ONCINA COVES 2003c, p. 176).

Esa situación reforzó la necesidad de aclarar los motivos que habían llevado a Koselleck a decantarse por esa clase de ordenación no obstante las obvias limitaciones que imponía. Su argumentación se basaba en que el formato escogido era la única alternativa práctica a las dificultades inherentes a una obra calificada no en vano de monumental. Aunque la idea original había consistido en publicar un solo volumen ordenado temáticamente, las dimensiones del proyecto y el desarrollo de su propuesta metodológica inclinaron finalmente la balanza hacia una estructura más aséptica (RICHTER 1996, p. 2).

La vertebración alfabética resultaba más manejable que una clasificación "sistemática o una agrupación de conceptos por temas como, por ejemplo, política, economía etc., o por dimensiones temporales, como, por ejemplo, conceptos tradicionales, conceptos que se transforman para abarcar una totalidad y neologismos". Optar por cualquiera de esas últimas opciones resultaba impracticable porque suponía apoyarse en un esquema interpretativo, subrayaba Koselleck, insostenible. En definitiva, "sólo la neutralidad del alfabeto ofrece la oportunidad de proceder con toda la elasticidad y adecuación necesarias al devenir histórico". Sin embargo, los "grupos de 
voces" no estaban ausentes de su estudio. La antonimia, la relación entre términos según su generalidad y especificidad y los conceptos paralelos mostraban la integración en el análisis de una cierta variedad de voces para calibrar la evolución histórica de sus usos (KOSELLECK 2009, p. 104). Koselleck no dudaba de que "los conceptos siempre están integrados en redes conceptuales" (KOSELLECK 2012, p. 47). En esa idea, basada en la vinculación natural que se establece entre conceptos y constelaciones de estos, incidirían posteriormente otros autores (BÖDEKER 2009, p. 167; FERNÁNDEZ SEBASTIÁN 2013, p. 57).

Sin embargo, esos argumentos no terminaron de convencer - por no resultar lo suficientemente elocuentes- aparte del gremio de historiadores a tenor de ulteriores reacciones a la presentación escogida por Koselleck para estructurar los resultados de su proyecto de investigación. En el debate con propuestas afines pertenecientes a la historia intelectual, J. G. A. Pocock y Quentin Skinner apuntaron, en ese sentido, algunos de los puntos débiles del GG y, por extensión, de la historia conceptual. Durante el congreso organizado por el German Historical Institute de Washington, por ejemplo, Pocock definió todo discurso o lenguaje como una entidad viva compuesta de muchas narrativas en constante interacción. Por consiguiente, ningún diccionario podía dar cuenta de un lenguaje concebido en esos términos. La mera ordenación alfabética de los conceptos no mostraba la interrelación existente entre ellos. Para el historiador de origen neozelandés, el orden de prelación entre ambas tentativas de investigación no ofrecía dudas (POCOCK 1996, p. 51). Eran, en conclusión, dos métodos con especificidades nacionales, culturales e históricas que no podían ser homogeneizados (ibíd., p. 58).

Skinner, por su parte, distanciándose de la noción de concepto koselleckiana, asimiló los conceptos a actos de lenguaje, por tanto, irrepetibles. Para Koselleck, esta interpretación implicaba negarles el carácter de sustancias capaces de tener una vida diacrónica, lo que tenía como corolario la imposibili- 
dad de una historia de conceptos. Era una crítica similar a la que tiempo antes había formulado Rolf Reichardt al plantear algunas de las principales reticencias al proyecto de su maestro, convertidas con el tiempo en tópicos. Entre ellas se encontraba precisamente la asunción de que los conceptos tienen un sentido propio al margen de las situaciones comunicativas (REICHARDT 1982; REICHARDT; SCHMITT 1985).

Koselleck aceptó que una precondición de cualquier análisis conceptual era el uso de los conceptos ligados a una situación y a unos hablantes con una carga de intenciones determinada. Sin embargo, al mismo tiempo, la historia conceptual excedía ese espacio interpretativo para liberarse del contexto concreto. El carácter único de los actos de habla se ve superado en la interpretación de Koselleck por la recepción y traducción a las que están sometidas voces utilizadas en el pasado por los hablantes de momentos históricos posteriores (KOSELLECK 1996, p. 62-63). De ahí la necesidad de combinar un acercamiento sincrónico con la dimensión diacrónica como única forma de hacer justicia a la convivencia de diferentes sedimentaciones semánticas. Por otro lado, la integración de los conceptos en los discursos haría compatibles ambos enfoques sin que por ello los primeros perdiesen autonomía (ibíd., p. 63-65; KOSELLECK 1993, p. 113).

En la estela de esa polémica, la tensión entre concepto (asociado al formato del diccionario) y lenguaje o discurso, al margen de las anteriores palabras de Koselleck, se ha convertido con el tiempo en un lugar común en los textos españoles. Y no sólo desde las disciplinas más involucradas, como la filosofía o la historia. Desde otros ámbitos también se ha abogado por la superación de una investigación centrada en el concepto para redirigirla, en su lugar, al texto, entendido, siguiendo la concepción de Ricoeur, como unidad mínima de sentido. Ir más allá del concepto sería una condición ineludible para hacer de la historia conceptual una herramienta útil, en este caso, en los estudios literarios (VARO 2013, p. 222). Otros artículos han propuesto ir incluso más allá del campo de la semiótica para 
insertar los conceptos en el terreno más amplio de las culturas políticas, lo que permitiría enlazar los conceptos y lenguajes con "modalidades no lingüísticas del discurso", con prácticas sociales y políticas (SÁNCHEZ-PRIETO 2009, p. 106-107).

Los diccionarios, en definitiva, aunque ajustados a la metodología que pergeñó Koselleck, no se han considerado como un fin en sí mismo, sino como medio para aplicar a ámbitos más amplios (SÁNCHEZ-PRIETO 2012, p. 498). La "transhumancia" de los conceptos entre épocas, saberes, esferas prácticas, iconologías, con repetidos viajes a y desde las metáforas, se integra, así, en la exigencia de ampliación del foco (ONCINA COVES 2014, p. 10). Los frutos de la investigación historiográfica, condensados en entradas de voluminosos diccionarios, habrían sido contribuciones valiosas, pero con una carga negativa asociada: el descuido de una reflexión crítica de sus presupuestos teóricos y resultados (ONCINA COVES 2013, p. 12-13).

Algunas vías de escape al peligro de solipsismo conceptual y al riesgo asociado de troquelar los conceptos apuntan en otra dirección que va más allá de invocar una compatibilidad más o menos expresa entre postulados de la Escuela de Cambridge y la historia de conceptos. En estos casos, se apela al potencial de la teoría que soporta la metodología koselleckiana como marco para rebasar los límites que plantea una investigación orientada al estudio de conceptos particulares. Sirva como botón de muestra el capítulo que Jörn Leonhard publicó en Conceptos políticos, tiempo e historia, donde destacó la necesidad de tomar en consideración campos semánticos, metáforas, transferencias, traducciones y las dicotomías básicas de la Histórica -como arriba/abajo, externo/interno, pronto/ tarde-, cuya utilidad radica, para el profesor de la Universidad de Friburgo, en su capacidad para estructurar la complejidad del mundo social (LEONHARD 2013, p. 383-384).

Esos elementos constituirían campos interrelacionados que permitirían escapar al efecto centrípeto de los conceptos tomados aisladamente. En este sentido, una de las dificultades des- 
tacada por buena parte de la práctica investigadora radica en definitiva en cómo hallar un modo de enmarcar una variedad amplia de conceptos en un esquema interpretativo que se pueda situar en un plano similar, con las especificidades propias de la BG, al de las epistemes foucaultianas o al de los lenguajes políticos analizados por Pocock, capaces de articular de forma convincente una miríada de conceptos en un discurso.

Sin abandonar del todo la iniciativa de Koselleck, ese esquema podría provenir, al menos parcialmente, del esbozo de su teoría de la historia, permaneciendo fiel a una historia de conceptos que contemple el eje sincronía-diacronía sin verse reducida a la primera dimensión, como sucede en algunos planteamientos provenientes de la llamada Escuela de Cambridge. Sobre esta cuestión parece necesaria una reelaboración crítica de la base teórica que lime el recelo de la razón histórica y el pesimismo sobre la deriva de la modernidad que impregnan el pensamiento de Koselleck y que se manifiestan en su Histórica. Privilegiar la exposición de pares dicotómicos que expresan conflictos eclipsa la capacidad, también anclada antropológicamente, de solucionarlos (ONCINA COVES 2003a, p. 32; FERNÁNDEZ TORRES 2018).

A partir de esa reelaboración de las condiciones trascendentales de la historia, el formato de lexicón podría superarse recurriéndose a unas estructuras peculiares caracterizadas por un alto grado de abstracción (asimilables a las categorías dicotómicas koselleckianas) que, no obstante, sea compatible con su presencia, incluso concreta, en el devenir histórico, mostrándose saturadas de historia (FERNÁNDEZ TORRES 2018, p. 541-542). En este sentido, sus diferentes manifestaciones encajarían en las estructuras de repetición esbozadas por Koselleck (2006). Esta flexibilidad permitiría agrupar conceptos cambiantes en torno a un tema virtualmente invariable.

La idea que recorre estos tanteos apunta, en definitiva, a la capacidad de la teoría de la historia para indagar en estructuras de baja historicidad, posibilitando con ello trazar áreas de investigación que exceden el formato de los dic- 
cionarios y habilitan el rediseño de la práctica investigadora. El propio Koselleck resaltó la prioridad de la teoría al señalar que la meta de la historia de conceptos era la Histórica (KOSELLECK 1993, p. 334).

Las críticas aquí expuestas y las soluciones esbozadas, que aluden a posibles limitaciones del proyecto, han sido en parte abordadas por quienes en España han adoptado parcialmente las propuestas de Koselleck. Sus repercusiones y la sensación de que es necesario ensanchar el campo para captar una realidad histórica que no se deja aprisionar (al menos no exclusivamente) en la malla de los conceptos han favorecido, de esa forma, una ampliación del abordaje y de las herramientas heurísticas aplicadas. Desde 2015, sin abandonar la base metodológica del proyecto germano, las modificaciones en el espectro temático y el marco temporal (que se expande en ambos sentidos), como también la suma de otras aproximaciones que se acometen mediante nuevos proyectos de investigación, pretenden asumir parte de las reservas hacia la historia de conceptos al tiempo que preservan lo esencial de ésta. Los conceptos individualmente considerados siguen ocupando un espacio importante, pero, junto a ellos, se encuentran ahora análisis que enfatizan la interacción en el seno de un grupo de voces y el tratamiento de discursos, metáforas y tropos, aspectos que ganan, en resumen, cada vez más relevancia en una reorientación de ciertas premisas que no sólo se deja sentir en España, sino también en el conjunto de la práctica iberoamericana de la historia de conceptos (FERNÁNDEZ SEBASTIÁN; FERNÁNDEZ TORRES 2017, p. 165).

\section{El espacio como unidad de análisis}

La celebración de una serie de encuentros entre los miembros del grupo orientado a la aplicación de la metodología koselleckiana a la investigación histórica a partir de 1994 terminó dando lugar a la publicación, ocho años después, de un primer diccionario dedicado al siglo XIX (FERNÁNDEZ SEBASTIÁN; FUENTES 2002). 
Se trata de una obra influida por el ejemplo (si bien redimensionándolo) del macrodiccionario germano.

La asunción de algunos presupuestos básicos de la BG no excluyó un acercamiento crítico de sus editores, que complementaron sus instrumentos con otras perspectivas procedentes de la Escuela de Cambridge, así como, en menor medida, por elementos propios del enfoque de Pierre Rosanvallon y de la lexicografía francesa. Como ya apuntó Reichardt, se llamó la atención, por ejemplo, sobre el uso restrictivo de las fuentes que prevalece en el GG debido a la centralidad otorgada a los grandes textos de la teoría política. Para erradicar o al menos paliar ese flanco débil, en la elaboración del diccionario español sus editores optaron de forma decidida por la inclusión de fuentes históricas menos formales como periódicos, manifiestos y folletos.

Más allá de las decisiones de carácter pragmático tomadas por los editores, lo cierto es que la aplicación del enfoque koselleckiano a la trama conceptual hispana ofrecía retos que podían convertirse estructuralmente en virtudes. Ante el sesgo filosófico que reduce el amplio campo del lenguaje en acción, el mundo hispano presenta una ventaja paradójica a la hora de llevar a cabo un trabajo que recoja con mayor fidelidad, más allá de las altas esferas del pensamiento, la presencia del lenguaje en la sociedad. La escasez de autores definidos canónicamente como "grandes pensadores", la ausencia de empresas intelectuales sistemáticas, el predominio de folletos, libelos y artículos periodísticos centrados en cuestiones de actualidad, pero que, sin embargo, no rehuyen reflexiones conscientes sobre cuestiones conceptuales complejas sirviéndose de un lenguaje febrilmente moderno; el itinerario irregular, en lo que a la producción intelectual se refiere, de muchos de sus mejores representantes (intelectuales, periodistas y políticos a la vez 0 sucesivamente) crean un marco en el que el lenguaje se muestra con una cierta "transparencia", siendo accesible con sus titubeos y contradicciones, con sus procesos de resemantización y significados concurrentes. Así, ese contexto constituiría 
-tomando prestada la expresión de Fernández Sebastián para referirse al ámbito iberoamericano- un genuino "laboratorio conceptual" (FERNÁNDEZ SEBASTIÁN 2008).

Privilegiando el mismo marco espacial, pero desplazando el eje temporal, un segundo diccionario continuaría la labor del proyecto inaugural. El mismo esquema metodológico se aplicaría en esta ocasión al estudio de conceptos del siglo XX (FERNÁNDEZ SEBASTIÁN; FUENTES 2008). Finalmente, fueron más de un centenar las voces tematizadas en ambos casos (alfabéticamente ordenadas). El elevado número de entradas imitaba el lexicón alemán a costa de una drástica limitación del espacio dedicado a cada concepto.

El siguiente eslabón que marcaría el desarrollo del grupo consistió en el traslado de la experiencia adquirida a un proyecto más ambicioso: la elaboración de un diccionario iberoamericano en varios tomos que diese cuenta del desarrollo de las distintas voces en cada uno de los territorios de los imperios luso e hispano y de sus estados sucesores. Por motivos obvios, en esta ocasión el modelo no podía calcarse del limitado a España a riesgo de hacer la empresa impracticable. En consecuencia, los conceptos elegidos fueron reducidos a diez en los dos tomos del Diccionario político y social del mundo iberoamericano publicados $(2009 ; 2014)$ a la vez que las unidades espaciales de análisis se multiplicaron (FERNÁNDEZ SEBASTIÁN 2009; 2014; FERNÁNDEZ SEBASTIÁN, FERNÁNDEZ TORRES 2017, p. 159160). La tercera fase, que se extiende hasta la actualidad, ha variado, en cambio, el modelo de organización, ampliado el espectro temático y modificado la forma de presentación del producto final, abandonando como fin la edición de un tercer diccionario.

Una justa valoración de la labor de la historia de conceptos en España en su vertiente historiográfica debe, por tanto, tener en cuenta entre sus aportaciones la de haber canalizado el aprendizaje obtenido con sus diccionarios territorialmente limitados hacia un marco espacial más amplio, sumando la dimensión internacional a una práctica que siem- 
pre corre el riesgo de discurrir por cauces nacionales. Esa expansión, necesaria para el caso concreto del estudio de las transferencias entre lenguas (KOSELLECK 1993, p. 69; Vorwort -prólogo- GG, vol. vii), podría ampliarse expresivamente para incluir las transferencias entre espacios con cierta autonomía histórica y hacerlo con flexibilidad al valorar su mayor o menor grado de similitud lingüística.

La extensión territorial del nuevo proyecto y las complejas relaciones basadas en un juego de afinidades y divergencias dentro de ese gran espacio iberoamericano favorecieron la subdivisión pragmática del proyecto en unidades de estudio espacialmente más manejables, coincidentes en su mayor parte con los límites de los actuales estados ( $y$, por tanto, con las respectivas academias nacionales), ilustrando un problema que ha acompañado todo el proceso de elaboración de los sucesivos diccionarios. La fricción que generaba esa delimitación espacial al aplicarse como una malla a los conceptos sociales y políticos fue evidente desde el principio para los participantes en el proyecto. Las razones pragmáticas y empíricas que primaron en la selección de las naciones como espacios de análisis no borraron la difícil convivencia entre el marco nacional como unidad territorial de análisis y la naturaleza de la noción de concepto, derivada de la peculiar carga teórica con la que se construye esta última categoría. Ésta posee un potencial que dinamita los marcos heredados de interpretación, en concreto aquellos que reducen el ámbito de estudio a los límites de los estados nación, precisamente al corsé jurídico-político que elabora la cosmovisión liberal, protagonista clave del periodo histórico estudiado.

La posibilidad de rebasar esos límites (que, obviamente, no implica la realización efectiva) tenía que esperar -entre otros factores - la aparición de unas herramientas cognitivas que transformasen los cimientos de la Weltanschauung liberal que se encontraba en su base. Ese rebasamiento reflexivo mediante la investigación de la génesis de los conceptos y de su estructura evolutiva permite un distanciamiento del zócalo 
real-ideal basado en entidades absolutas tanto jurídicas como sociales que sustentan el mundo occidental desde principios del siglo XIX. La historiografía previa se encontraba inconscientemente en una situación asimilable a aquella en la que el barón de Münchhausen intentaba escapar de una ciénaga tirándose de la coleta. La imposibilidad de concebir una estrategia investigadora fuera del marco decimonónico sólo podía ser superada mediante un desplazamiento cultural de los presupuestos del positivismo, que se vio aceleradamente minado desde finales del siglo XIX. De este modo se fue preparando el terreno para el giro lingüístico y se abrió la posibilidad de concebir la historia humana en su dimensión conceptual, culminando, en cierto modo, la concepción herderiana del ser humano como criatura lingüística.

La historiografía se había movido, en definitiva, dentro de un marco plagado de entidades que aceptaba como sólidas y como guías de la investigación. El Estado, la nación, las razas, los individuos, la razón eran los vectores que estructuraban el tiempo y la historia en un despliegue más o menos coherente. Frente a esto, la intuición de que la estructura temporal se deposita en los conceptos implica un cambio drástico en la percepción de esas entidades ordenadoras y jerarquizadoras de la experiencia que obliga a poner entre paréntesis su pertinencia o, al menos, a reconocer el carácter pragmático y volátil de su elección como marcos que recortan el objeto de estudio.

La conversión de esas palabras-instituciones en unidades para su análisis en el esquema de la historia de conceptos provoca, en resumen, su pérdida de capacidad para encuadrar y limitar la reflexión al poner al descubierto su génesis y su carácter procesual, es decir, su naturaleza coyuntural. El desvelamiento de su historicidad las lamina funcionalmente, inhabilitándolas para erigirse en faros interpretativos de la investigación histórica. Cuando la atención se gira hacia los fundamentos que han posibilitado su propia actividad reflexiva también se revuelve contra ellos. De ese modo, la interpretación del lenguaje como instancia histórica basal implicaba una 
reconsideración de sus expresiones "materiales" y sus correspondientes jerarquías. La historización de los conceptos sólo podía terminar, por tanto, en una relativización de la función estructuradora de la experiencia de los constructos jurídicos, políticos, sociales y también económicos que eran sus correlatos. Por eso, el recorrido de esos proyectos de investigación se encuentra inevitablemente atravesado por la tensión entre algunos de sus presupuestos teórico-metodológicos y las elecciones pragmáticas. Sin embargo, lejos de conducir a un marasmo creativo, esa tensión se ha revelado como fuente de reflexión y de concienciación de los límites y aporías a los que se enfrenta toda empresa historiográfica.

En este sentido, la historia de conceptos no sólo parece presionar hacia una separación neta de marcos nacionales, sino también entre ámbitos espaciales de distinta naturaleza discursiva. El proyecto de un diccionario iberoamericano, recogiendo ese rasgo, aspiró a quebrar una estructuración que distingue entre zonas territoriales (y cabría añadir que también ideológicas) creadoras de discursos y zonas receptoras, impulso que se utilizó también como argumento a favor de modelar y volcar el producto de la investigación en un formato de lexicón, centrado en los conceptos más que en los lenguajes. Escoger los primeros como vía de acceso a la comprensión del proceso histórico permitiría pluralizar las experiencias de la modernidad al desacoplarse, por ejemplo, del esquematismo alimentado por los prejuicios asociados a las tradicionales distinciones netas entre lenguajes liberales y republicanos. Los conceptos no pertenecen a un modelo de discurso, sino que transitan entre ellos (FERNÁNDEZ SEBASTIÁN 2009, p. 38).

Es posible que Hans Ulrich Gumbrecht no conociese ese argumento o que no le haya concedido peso cuando, en 2011, calificó de "súbita elefantiasis histórico-conceptual en castellano" la acelerada producción de "pirámides espirituales" o diccionarios (BÖDEKER 2011 apud ONCINA COVES 2013, p. 14-15). En todo caso, los editores de los diccionarios españoles han sido conscientes de las ventajas e inconvenientes 
derivados de la ordenación alfabética y nacional de los conceptos y asimismo del delineamiento cronológico de su historia. Entre las primeras, estaba la facilidad de consulta; las limitaciones, en cambio, eran fruto de "disecar en cierto modo la materia viva de los debates" (FERNÁNDEZ SEBASTIÁN; FUENTES 2008, p. 16).

\section{Periodización}

La periodización escogida concita asimismo buena parte de las renuencias al proyecto de Koselleck. A pesar de que en los artículos del GG se hace un análisis de los conceptos desde su origen en la Antigüedad, el diccionario de más de 7.000 páginas asume como premisa fundamental la existencia de un periodo de profunda transformación conceptual situado entre 1750 y 1850 . El término con el que se designó esa etapa de cambio es de sobra conocido: una expresión, la de Sattelzeit, que no terminó de satisfacer a su propio creador. Koselleck dudaba de su pertinencia debido a su ambigüedad y debilidad teórica. De hecho, ese periodo a horcajadas, inicialmente concebido para facilitar la financiación del GG, con el tiempo oscureció más que aclaró el proyecto. Para Koselleck, hubiese sido más acertado utilizar Schwellenzeit (periodo umbral), una metáfora menos ambigua (FERNÁNDEZ SEBASTIÁN; FUENTES 2006).

El testigo de la defensa de esa periodización lo recogieron en cierto modo Javier Fernández Sebastián y Juan Francisco Fuentes, obligados a justificar la elección del siglo XIX como delimitación temporal del primer volumen de su diccionario de conceptos políticos y sociales (FERNÁNDEZ SEBASTIÁN; FUENTES 2002). Como ya lo he mencionado, la validez de ese supuesto crucial que los directores del proyecto asumieron como aplicable al caso español fue ampliada territorialmente en el proyecto posterior destinado al conjunto del espacio iberoamericano (dirigido en esta ocasión en solitario por Fernández Sebastián). 
La aplicación de un tiempo a horcajadas como herramienta heurística en el contexto decimonónico español se encontraría fundamentada por la presencia de una serie de rasgos que confirmarían algunos de los supuestos que describen la naturaleza de ese periodo especial. La extensión de esos supuestos al área iberoamericana no pareció presentar mayores dificultades. En la introducción al primero de los diccionarios, se asumió como punto de partida la pertinencia de la Sattelzeit y de las correspondientes cuatro dimensiones señaladas por Koselleck. A los cuatro rasgos que caracterizan la gran transformación conceptual se añadieron la emocionalización (ligada al aumento de las expectativas y a la lucha partidista, intensamente vivida) y la internacionalización, que se tradujo en la aparición de "occidentalismos", conviviendo de forma aparentemente paradójica con una nacionalización del lenguaje manifiesta en Europa, sobre todo, a finales del siglo XIX (FERNÁNDEZ SEBASTIÁN 2009, p. 29-31). Este extremo ya había sido señalado un año antes en el diccionario dedicado a la España del siglo $\mathrm{XX}$, que contó con apenas 20 acuñaciones originales ("catalanismo", "caudillo", "exilio", "franquismo", "Hispanidad"...). El resto, hasta completar el lexicón, "pueden considerarse europeísmos" (FERNÁNDEZ SEBASTIÁN; FUENTES 2008, p. 16).

La opinión favorable a la existencia de una variante autóctona de la Sattelzeit no parece haber encontrado una especial resistencia. En cambio, han existido oscilaciones respecto a la determinación de sus límites, así como a una ampliación del uso del método a otros periodos históricos. El alcance de la investigación histórica en su eje temporal se vio, en ese sentido, modificado sustancialmente durante el proceso de gestación y publicación del segundo volumen dedicado a los conceptos sociales y políticos en España. En esta ocasión, el siglo XX delineaba el perímetro cronológico en el que se volcaron los recursos metodológicos ya utilizados con su predecesor. El desplazamiento del marco temporal planteaba algunas cuestiones importantes, apuntadas en parte por los editores, que afectaban al método y abrían un espacio a la reformulación, al 
menos en forma de preguntas, de la compleja noción de tiempo histórico manejada por Koselleck.

\section{Historia conceptual, modernidad e historia actual}

El proyecto koselleckiano puede entenderse como un esfuerzo de aclaración del presente, como su diagnóstico, y esto pasa, inevitablemente, por encarar la naturaleza del tiempo histórico y su relación con la modernidad (ROMERO CUEVAS 2010, p. 107). De nuevo, las dos formas de afrontar este aspecto siguen, grosso modo, las líneas de la adscripción académica.

Por un lado, a este tema ha prestado una atención especial Faustino Oncina, cuyo diálogo con Koselleck persigue un aprovechamiento crítico de sus materiales, sobre todo de las herramientas heurísticas, sin asumir por ello, como ya sabemos, las premisas y conclusiones impregnadas de un sesgo conservador crítico con la modernidad (ONCINA COVES 2009). Desde luego, junto a Koselleck, en los textos españoles que abordan el tema, aparecen mencionados otros autores que han indagado sobre la naturaleza del tiempo histórico. Las referencias a François Hartog y su categoría de regímenes de historicidad y a Harmut Rosa no resultan, por tanto, sorprendentes en este contexto (DÁVILA 2017).

Desde la historiografía, por otro lado, el acercamiento al factor temporal ínsito en los conceptos se ha llevado a cabo desde la práctica. Es el caso de un interesante trabajo de Pablo Sánchez León, que, desde una perspectiva que busca poner en conexión grupos de conceptos, aborda una pareja de voces clave en la articulación de la variable tiempo inscrita en el lenguaje: "decadencia" y "regeneración" (SÁNCHEZ LEÓN 2013). Su interés por explorar relaciones entre distintos conceptos ya se había puesto de manifiesto anteriormente al ocuparse de los términos políticos "democracia" y "demagogia" (SÁNCHEZ LEÓN 2012). 
Por su parte, en el haber del diccionario que se ocupa de 125 conceptos políticos y sociales del siglo XX, encontramos la identificación de ciertos vectores que modifican sustancialmente el paisaje lingüístico respecto al del siglo anterior, tales como el desarrollo tecnológico, las cuestiones medioambientales, la biotecnología, las comunicaciones; además de un aumento de conceptos con claras referencias espaciales a costa de los temporales; en suma, la señalización de las grandes transformaciones que sufrió España (y por extensión, el mundo occidental) a lo largo de ese siglo en materia política, social y económica (FERNÁNDEZ SEBASTIÁN; FUENTES 2008, p. 54, 72 y 76).

Esos cambios, considerados en su conjunto, apuntan a una transformación del mapa conceptual que se acelera en el último cuarto del siglo XX y que cabría calificar como cualitativa. Así parecen captarlo los editores al servirse del símil de un "diccionario bilingüe" para expresar las relaciones que se establecen, con continuas referencias cruzadas, entre el lenguaje decimonónico y el propio del siglo XX. Esto se manifestaría en

el estancamiento de algunos conceptos entre uno y otro siglo, [en] el cambio de significado o de magnitud de otros, [...] la irrupción de nuevos términos $y$, en definitiva, [en] los fenómenos de continuidad, ruptura y deslizamiento que se registran entre ambos periodos (FERNÁNDEZ SEBASTIÁN; FUENTES 2008, p. 52).

Esta acumulación de indicadores parecería diagnosticar el rebasamiento de un nuevo umbral epocal, es decir, sugeriría que el siglo XX posee una autonomía que lo distingue crucialmente de su pasado inmediato, de la Sattelzeit.

De ese modo, durante la fase de sustitución parcial de un marco por otro se asistiría a la recomposición de los conceptos clave respecto a los predominantes en el siglo anterior (ibíd., p. 46). Sin embargo, sería una renovación insuficiente del vocabulario político y social que provocaría la sensación, entre algunos coetáneos, de orfandad conceptual para expresar de forma precisa las transformaciones que tuvieron 
(y tienen) lugar, especialmente a partir de la segunda mitad del siglo XX (ibíd., p. 47 y 50-51). La potencia de la historia de conceptos para una historia del presente y del porvenir no carece, en definitiva, de defensores (ONCINA COVES 2013, p. 37).

A pesar del valor de las intuiciones sobre los rasgos peculiares de la nueva época que comienza en torno al cambio de siglo, el proyecto historiográfico se resiente de la falta de una reflexión más amplia sobre la forma en la que el nuevo marco cronológico afecta a la metodología y, por ende, a la naturaleza de los conceptos. De haber sido abordado, ese cuestionamiento hubiese anticipado de forma más precisa las propuestas posteriores de Christian Geulen en Alemania, quien, por otro lado, coincide en buena medida con los editores españoles en la identificación de los indicadores del cambio. Esta coincidencia, sin embargo, no llevó a los últimos a elaborar un diagnóstico más profundo del lenguaje de nuestro pasado más reciente que permitiera indagar de qué forma las modificaciones acaecidas durante el siglo XX afectan a la metodología koselleckiana aplicada al nuevo espacio temporal (GEULEN 2010; 2012).

\section{Conclusiones}

Me gustaría dedicar estos últimos párrafos a subrayar uno de los aspectos más relevantes, si no el más destacado, en mi opinión, que puede extraerse de esta aproximación a los itinerarios que ha seguido la historia de conceptos en España. Se trata de la dificultad general para conectar teoría y práctica de la investigación, una ligazón endeble entre dos facetas particularmente importantes en este enfoque intelectual que parece responder a las constricciones que las diferentes disciplinas y sus respectivas estructuras y tradiciones académicas parecen ejercer sobre la tan reclamada transdisciplinariedad. No se trata, en estas últimas reflexiones, de ocultar el creciente valor de la producción intelectual en ese campo, lo que ya ha sido puesto de manifiesto, sino de apuntar un límite que impide sa- 
car más partido al proyecto de una historia del lenguaje capaz de vincular la profundidad teórica con el trabajo empírico de las fuentes.

A pesar de las interacciones (tanto a nivel institucional como en el conjunto de trabajos publicados), es visible un divorcio entre la reflexión teórica y la investigación empírica que ha desconectado hasta cierto punto las cuestiones metahistóricas, la generación de la temporalidad, de la práctica. Religar ambas dimensiones para dar cuenta de procesos más amplios mediante la formulación de problemas (que parcialmente pueden plantearse desde la teoría) a los que dar una respuesta se traduciría, como muestran de hecho algunos de los proyectos en marcha, en una ampliación de los formatos de presentación de los resultados que añadiría riqueza a un paisaje en el que ha predominado la estructura del lexicón, sobre cuyas entradas se cierne, a pesar de los importantes esfuerzos en contra, la espada de Damocles de una historia descriptiva de los diferentes usos de un término. La producción historiográfica aumentaría de este modo el valor de la inestimable tarea que ha supuesto la elaboración de diccionarios en las últimas décadas.

En el campo de preocupaciones propio de una historia de conceptos, conservar una vinculación productiva entre la dimensión teórica y la práctica historiográfica podría, entre otras vías, pasar, por tanto, por formular y responder provisionalmente a una serie de preguntas relativas a la posibilidad de hacer una historia diacrónica de conceptos que gire en torno a un problema teóricamente fundamentado. De entre las posibles cuestiones a plantear, algunas podrían formularse como sigue: ¿cómo hacer una historia de conceptos que crezca sobre los trabajos previos y que esquive al mismo tiempo terminar reducida a un concepto o a conceptos parcialmente sinónimos, paralelos, asimétricos o emparentados onomasiológicamente?; ¿cómo hacerlo sin caer en un análisis sincrónico por un exceso de estudio filológico o en una monografía por exceso de historia social?; ¿y de qué manera lograrlo sin abrazar a su vez 
alguna de las propuestas de análisis que privilegian los lenguajes políticos y discursos, abandonando con ello la autonomía de la historia de conceptos como matriz intelectual explicativa? Se trata de saber, en definitiva, si una aproximación teórica y metodológica inspirada en la semántica histórica de Reinhart Koselleck permite plantear preguntas y ofrecer respuestas que no puedan expresarse y contestarse desde otras ópticas. Quizá esta búsqueda exija elevarse un poco en el diagrama de la historia de conceptos para encontrar, desde un espacio teórico anexo, el lugar de formulación de esas preguntas.

Para aclarar este extremo, habría que subrayar primero que todo foco debe respetar uno de los ejes clave de la historia de conceptos, la dimensión diacrónica de este enfoque, es decir, el perfilado de una historia a largo plazo de los conceptos como principio irrenunciable. A partir de aquí, la dificultad estriba en hallar una referencia que justifique una articulación capaz de identificar nodos de transformación conceptual que, desde una perspectiva sincrónica, se integren en una amplia línea temporal. Con una cierta dosis de inevitable arbitrariedad hay que hallar, en definitiva, una posición estructuradora de la investigación. Se trataría, en palabras de Lucien Febvre, de identificar el problema de la historia que se quiere investigar, un problema que, en el marco de la intensa apuesta teórica koselleckiana, pasa por asumir que la teoría dirige las preguntas como una operación trascendental. $Y$ este adjetivo ya nos da una pista que seguir.

Como alternativa siempre puede esperarse que un conocimiento exhaustivo del contexto intelectual y político canalice el estudio sistemático de las fuentes documentales y revele patrones, recurrencias y rupturas. Sin duda es una vía de acceso al conocimiento histórico que reduce, sin expulsarla necesariamente, el papel de la teoría como indicadora del objeto de estudio. La dirección contraria, sin embargo, resalta el papel del aparato teórico como guía. Y si algo caracteriza a la historia de conceptos es su fuerte impronta teórica. ¿Por qué, por tanto, no buscar en su marco una respuesta a los límites que 
tradicionalmente ha padecido la práctica de la historia conceptual y que no han hecho fácil cohonestar la localización de un problema sin abandonar el territorio de la BG, es decir, sin renunciar a esbozar los cambios conceptuales a largo plazo? El alcance de este enfoque y su productividad se hallan ligados en ese sentido a una respuesta positiva a la anterior pregunta.

Como ha quedado puesto de manifiesto, ha habido sugerencias que han ido en ese sentido. La incompleta Histórica de Koselleck, una vez superada la incomodidad generada por la naturaleza simultáneamente analítica y ontológica que puede derivarse de ese presupuesto, ofrece un anclaje para orientar una investigación capaz de explicar procesos complejos a largo plazo sin quedar supeditada a unos conceptos concretos, ayudando en el proceso a localizar los momentos de resemantización o de emergencia de nuevas fórmulas expresivas. Hay que recordar que su teoría de la historia toca condiciones metahistóricas, rasgos antropológicos con un bajo grado de historicidad, una historia casi inmóvil que alimenta en niveles superiores la fragmentación creciente de formas de vida. Una reformulación de la Histórica podría registrar estructuras interpretativas con mayor capacidad explicativa que las categorías dicotómicas y que sean susceptibles de ser sometidas, como le gustaba repetir a Koselleck, al derecho de veto de las fuentes (FERNÁNDEZ TORRES 2018).

\section{REFERENCIAS}

ABELLÁN, Joaquín. Historia de los conceptos (Begriffsgeschichte) e historia social. A propósito del diccionario Geschichtliche Grundbegriffe. In: CASTILLO, Santiago (ed.). La historia social en España: Actualidad y perspectivas. Madrid: S. XXI, 1991. p. 47-63.

BÖDEKER, Hans Erich. Sobre el perfil metodológico de la historia conceptual: Temas, problemas, perspectivas". Historia y Grafía, n. 32, p. 131-168, 2009. 
BÖDEKER, Hans Erich. Conferencia: Wie deutsch waren die Geisteswissenschaften - und sollten sie sein? Simposio anual del Centro de Investigación Literaria y Cultural de Berlín (Internationale Wirkungsgeschichte der deutschsprachigen Geisteswissenschaften und ihrer Sprache), 2 dic. 2011.

CAPELLÁN DE MIGUEL, Gonzalo. Los "momentos conceptuales": una nueva herramienta para el estudio de la semántica histórica. In: FERNÁNDEZ SEBASTIÁN, Javier; CAPELLÁN DE MIGUEL, Gonzalo. Lenguaje, tiempo y modernidad. Ensayos de historia conceptual. Santiago de Chile: Globo Editores, 2011. p. 113-152.

CAPELLÁN DE MIGUEL, Gonzalo. El concepto democracia: momentos, significados e imágenes en la "larga duración" (Una propuesta para repensar la historia conceptual en el mundo iberoamericano). Ariadna histórica. Lenguajes, conceptos, metáforas, p. 101-146, 2018. Disponible en: https://www.ehu.eus/ojs/index.php/Ariadna/article/ view/20177. Consultado el: 18 dic. 2018.

DÁVILA, Estefanía. La pregunta por el presente. Una genealogía del tiempo en la Modernidad. Sociología histórica, n. 7, p. 121-141, 2017.

FERNÁNDEZ SEBASTIÁN, Javier; FUENTES ARAGONÉS, Juan Francisco (dirs.). Diccionario político y social del siglo XIX. Madrid: Alianza Editorial, 2002.

FERNÁNDEZ SEBASTIÁN, Javier; FUENTES ARAGONÉS, Juan Francisco. A manera de introducción. Historia, lenguaje y política. Ayer, n. 53, p. 11-26, 2004.

FERNÁNDEZ SEBASTIÁN, Javier. Textos, conceptos y discursos políticos en perspectiva histórica. Ayer, n. 53, p. 131-151, 2004. 
FERNÁNDEZ SEBASTIÁN, Javier; FUENTES ARAGONÉS, Juan Francisco. Historia conceptual, memoria e identidad, (entrevista a Reinhart Koselleck). Revista de Libros, n. 111-112, 2006.

FERNÁNDEZ SEBASTIÁN, Javier; FUENTES ARAGONÉS, Juan Francisco (dirs.). Diccionario político y social del siglo XX español. Madrid: Alianza Editorial, 2008.

FERNÁNDEZ SEBASTIÁN, Javier. El mundo atlántico como laboratorio conceptual, 1750-1850. Jahrbuch für Geschichte Lateinamerikas $=$ Anuario de Historia de América Latina (JbLA), n. 45, p. 1-7, 2008.

FERNÁNDEZ SEBASTIÁN, Javier. Ex innovatio traditio/Ex traditio innovatio: Continuidad y ruptura en la historia intelectual. In: ONCINA COVES, Faustino (ed.). Tradición e innovación en la historia intelectual: Métodos historiográficos. Madrid: Biblioteca Nueva, 2013. p. 51-74.

FERNÁNDEZ SEBASTIÁN, Javier (dir.). Diccionario político y social del mundo iberoamericano. Madrid: Centro de Estudios Políticos y Constitucionales, 2009 y 2014. 11 vols., 2 tomos.

FERNÁNDEZ TORRES, Luis. Las constantes antropológicas de la Histórica de Koselleck. Una propuesta de ampliación. Isegoría, Revista de filosofía moral y política, n. 59, p. 527-551, 2018.

FERNÁNDEZ SEBASTIÁN, Javier; FERNÁNDEZ TORRES, Luis. Iberconceptos: un proyecto de investigación en red: cuestiones teórico-metodológicas y organizativas. Spagna contemporánea, n. 51, p. 153-175, 2017.

GALINDO HERVÁS, Alfonso. El antiliberalismo como clave de la obra de Koselleck. Araucaria, Revista Iberoamericana de Filosofía, Política y Humanidades, n. 21, p. 44-62, 2009. 
GEULEN, Christian. Plädoyer für eine Geschichte der Grundbegriffe des 20. Jahrhunderts. Zeithistorische Forschungen/Studies in Contemporary History, n. 7, 2010. Disponible en: https://zeithistorische-forschungen. de/1-2010/id\%3D4488. Consultado el: 5 feb. 2014.

GEULEN, Christian; HOFFMANN, Stefan-Ludwig; KOLLMEIER, Kathrin; STEINMETZ; Willibald; SARASIN, Phillip; LÜDTKE, Alf,. Geschichtliche Grundbegriffe Reloaded? Writing the Conceptual History of the Twentieth Century. Contributions to the History of Concepts, v. 7, n. 2, p. 78-128, 2012.

GÓMEZ RAMOS, Antonio. El trabajo público de los conceptos. Isegoría, Revista de filosofía moral y política, n. 37, p. $185-196,2007$.

GÓMEZ RAMOS, Antonio. Conceptos y redes: sobre sujetos de las constelaciones e historia conceptual. In: ONCINA COVES, Faustino (coord.) Constelaciones. Valencia: Pre-Textos, 2017. p. 31-50.

HABERMAS, Jürgen. Crítica de la filosofía de la historia. In: HABERMAS, Jürgen. Perfiles filosófico-políticos, Madrid: Taurus, 1975 [1960].

HERNÁNDEZ MARCOS, M. Historia conceptual y lexicografía. Una introducción panorámica. In: PONCELA, A. (coord.). Filosofía y Sociedad. Sugerencias Didácticas y metodológicas para la docencia en la Educación Secundaria, Celarayn, CD, 2010.

HÖLSCHER, Lucian. Los fundamentos teóricos de la historia de los conceptos (Begriffsgeschichte). In: GORASURRETA, Francisco Javier Caspistegui; GORTÁZAR, Ignacio Olábarri (coord.). La "nueva" historia cultural: la influencia del postestructuralismo y el auge de la interdisciplinariedad. Madrid: Ed. Complutense, 1996. p. 69-82. 
JIMÉNEZ RUIZ, Juan Luis. Lenguaje e Historia: A propósito de la controversia entre Koselleck y Gadamer. E.L.U.A., no 13 , p. 281-296, 1999.

KOSELLECK, Reinhart. Crítica y Crisis del mundo burgués. Madrid: Rialp, 1965.

KOSELLECK, Reinhart. Preussen zwischen Reform und Revolution. Allgemeines Landrecht, Verwaltung und soziale Bewegung von 1791 bis 1848. Stuttgart: E. Klett, 1967a.

KOSELLECK, Reinhart. Richtlinien für das Lexicon politish-sozialer Begriffe der Neuzeit. Archiv für Begriffsgeschichte, n. 9, p. 81-90, 1967b.

KOSELLECK, Reinhart. Krise. In: BRUNNER, Otto; CONZE, Werner; KOSELLECK, Reinhart. Geschichtliche Grundbegriffe: historisches Lexikon zur politisch-sozialen Sprache in Deutschland. Stuttgart: Klett-Cotta, v. 3, 19721997. p. 651-675.

KOSELLECK, Reinhart. Vorwort -prólogo-. In: BRUNNER, Otto; CONZE, Werner; KOSELLECK, Reinhart. Geschichtliche Grundbegriffe: historisches Lexikon zur politisch-sozialen Sprache in Deutschland. Stuttgart: Klett-Cotta, v. 7, 1972-1997.

KOSELLECK, Reinhart. Futuro pasado: para una semántica de los tiempos históricos. Barcelona: Paidós, 1993.

KOSELLECK, Reinhart. A Response to Comments on the Geschichtliche Grundbegriffe. In: LEHMANN, Harmut; RICHTER, Melvin (eds.). The meaning of historical terms and concepts. New studies on Begriffsgeschichte. Washington: German Historical Institute, 1996. p. 59-70.

KOSELLECK, Reinhart; GADAMER, Hans-Georg. Historica y hermenéutica. Introducción de José Luis Villacañas y Faustino Oncina. Barcelona: Paidós, 1997. 
KOSELLECK, Reinhart. Los estratos del tiempo: estudios sobre la historia. Edición de Elías Palti. Barcelona: Paidós, 2001.

KOSELLECK, Reinhart. Aceleración, prognosis y secularización. Edición y traducción de Faustino Oncina Coves. Valencia: Pretextos, 2003.

KOSELLECK, Reinhart. Estructuras de repetición en el lenguaje y en la historia. Revista de Estudios Políticos, n. 134, p. 17-34, 2006.

KOSELLECK, Reinhart. Un texto fundacional de Reinhart Koselleck: introducción al Diccionario histórico de conceptos político-sociales básicos en lengua alemana. Revista Anthropos, n. 223, p. 92-105, 2009. Traducción y notas de Luis Fernández Torres.

KOSELLECK, Reinhart. Historias de conceptos. Estudios sobre semántica y pragmática del lenguaje político y social. Traducción de Luis Fernández Torres. Madrid: Trotta, 2012.

LEONHARD, Jörn. Lenguaje, experiencia y traducción: hacia una dimensión comparativa. In: FERNÁNDEZ SEBASTIÁN, Javier; CAPELLÁN DE MIGUEL, Gonzalo (eds.). Conceptos políticos, tiempo e historia: nuevos enfoques en historia conceptual. Santander: Editorial de la Universidad de Cantabria - McGraw-Hill Interamericana de España, D.L., 2013. p. 377-404.

MARTÍN GÓMEZ, María. La introducción en España de la historia conceptual. Azafea, Rev. filos., n. 13, p. 257-276, 2011. 
MELTON, James Van Horn. Otto Brunner and the Ideological Origins of Begriffsgeschichte. In: LEHMANN, Harmut; RICHTER, Melvin (eds.). The meaning of historical terms and concepts. New studies on Begriffsgeschichte, Washington D. C.: German Historical Institute, 1996. p. 21-33.

ONCINA COVES, Faustino. Prólogo a. In: KOSELLECK, Reinhart. Aceleración, prognosis y secularización. Valencia: Pretextos, 2003. p. 11-33.

ONCINA COVES, Faustino. Historia conceptual, Histórica y modernidad velociferina: diagnóstico y pronóstico de Reinhart Koselleck. Isegoría, Revista de filosofía moral y política, n. 29, p. 225-237, 2003b.

ONCINA COVES, Faustino. Historia conceptual y hermenéutica. Azafea, Revista de filosofía, n. 5, p. 161-190, 2003c.

ONCINA COVES, Faustino. Necrológica del Outsider Reinhart Koselleck: el «historiador pensante» y las polémicas de los historiadores. Isegoría, Revista de filosofía moral y política, n. 37, p. 35-61, 2007.

ONCINA, Faustino. Historia conceptual, Ilustración y Modernidad. Barcelona: Anthropos, 2009.

ONCINA COVES, Faustino. Historia Conceptual: calgo más que un método? (a modo de introducción). In: ONCINA COVES, Faustino (ed.). Tradición e innovación en la historia intelectual. Métodos historiográficos. Madrid: Biblioteca Nueva, 2013. p. 11-38.

ONCINA COVES, Faustino. Nomadismo conceptual y autodeterminación como destino. A modo de introducción. In: ONCINA COVES, Faustino; MIRAVET, Nerea; VIZCAÍNO REBERTOS, Héctor (coords.). Conceptos nómadas. Autodeterminación. Valencia: Publicacions de la Universitat de València, 2014. p. 9-24. 
ONCINA COVES, Faustino. Historia conceptual y método de las constelaciones. In: ONCINA COVES, Faustino (coord.). Constelaciones. Valencia: Pre-Textos, 2017, p. 11-30.

POCOCK, J.G.A. Concepts and Discourses: A Difference in Culture? Comment on a Paper by Melvin Richter. In: LEHMANN, Harmut; RICHTER, Melvin (eds.). The meaning of historical terms and concepts. New studies on Begriffsgeschichte. Washington: German Historical Institute, 1996. p. 47-58.

REICHARDT, Rolf. Zur Geschichte politisch-sozialer Begriffe in Frankreich zwischen Absolutismus und Restauration. Zeitschrift fur Literaturwissenschaft und Linguistik, n. 47, p. 49-74, 1982.

REICHARDT, Rolf; SCHMITT, E. Handbuch politisch-sozialer Grundbegriffe in Frankreich 16801820 (Manual de conceptos político-sociales fundamentales en Francia 1680-1820). Múnich: R. Oldenbourg, 1985.

RICHTER, Melvin. Appreciating a Contemporary Classic: The Geschichtliche Grundbegriffe and Future Scholarship. In: LEHMANN, Harmut; RICHTER, Melvin (eds.). The meaning of historical terms and concepts. New studies on Begriffsgeschichte, Washington: German Historical Institute, 1996. p. 7-19.

ROMERO CUEVAS, José Manuel. La Histórica de R. Koselleck y la apertura de la historia. Conceptos, Revista de Investigación Graciana, n. 5, p. 91-103, 2008.

ROMERO CUEVAS, José Manuel. El diagnóstico de la modernidad en la historia conceptual de Koselleck. In: ONCINA COVES, Faustino. Palabras, conceptos, ideas: estudios sobre historia conceptual. Barcelona: Herder, 2010. p. $107-128$. 
RORTY, Richard. The linguistic turn. Recent essays in philosophical method. Chicago: The University of Chicago Press, 1967.

RUIZ TORRES, Pedro. El tiempo histórico. Eutopías, $2^{a}$ Época, vol. 71, 1994.

SÁNCHEZ LEÓN, Pablo. El reverso del orden y el orden de los conceptos: democracia y demagogia en el liberalismo hispano. In: PÉREZ LEDESMA, Manuel (ed.). Lenguajes de modernidad en la Península Ibérica. Madrid: Universidad Autónoma de Madrid, 2012. p. 216-248.

SÁNCHEZ LEÓN, Pablo. Decadencia y regeneración. La temporalidad en los conceptos fundamentales de la modernidad española. In: FERNÁNDEZ SEBASTIÁN, Javier; CAPELLÁN DE MIGUEL, Gonzalo (eds.). Conceptos políticos, tiempo e historia. Nuevos enfoques en historia conceptual. Santander: Universidad de Cantabria/McGraw-Hill, 2013. p. 271-302.

SÁNCHEZ-PRIETO, Juan María. De los conceptos a las culturas políticas. Perspectivas, problemas y métodos. Revista Anthropos, Barcelona, n. 223, p. 106-118, 2009.

SÁNCHEZ-PRIETO, Juan María. Reinhart Koselleck: La interdisciplinariedad de la Historia. Memoria y Civilización, Universidad Pública de Navarra, n. 15, p. 475-499, 2012.

VARO ZAFRA, Juan. Historia conceptual y estudios literarios. Castilla, Estudios de Literatura, n. 4, p. 204-228, 2013.

VILLACAÑAS, José Luis. Prólogo a. In: CHIGNOLA, S.; DUSO, G. Historia de los conceptos y filosofía política. Madrid: Biblioteca Nueva, 2009.

WITTGENSTEIN, Ludwig. Investigaciones filosóficas. Barcelona: Crítica, 1988. 
WITTGENSTEIN, Ludwig. Tratado lógico-filosófico.

Logisch-philosophische Abhandlung. Valencia: Tirant lo Blanch, 2016.

\section{AGRADECIMIENTOS E INFORMACIÓN}

\section{Luis Fernández Torres}

procusto11@hotmail.com

https://orcid.org/0000-0001-5023-3150

Universidad del País Vasco / Euskal Herriko Unibertsitatea

Lejona

Vizcaya

España 